\title{
GIANT MAGNETORESISTANCE IN MELT-SPUN Co-Cu MODIFIED BY RARE EARTHS
}

\author{
B. IDZIKOWSKI ${ }^{a, b *}$, U.K. RÖSSLER ${ }^{a}$, \\ A. HANDStein ${ }^{a}$, K. NenKov ${ }^{a \dagger}$ AND K.-H. MÜLleR ${ }^{a}$ \\ ${ }^{a}$ Institut für Festkörper- und Werkstofforschung Dresden \\ P.O. Box 270016, 01171 Dresden, Germany \\ ${ }^{b}$ Institute of Molecular Physics, Polish Academy of Sciences \\ M. Smoluchowskiego 17, 60-179 Poznań, Poland
}

Samples of the composition $\mathrm{RE}_{x} \mathrm{Co}_{20} \mathrm{Cu}_{80-x}, \mathrm{RE}=\mathrm{Sm}, \mathrm{Gd}$ or $\mathrm{Dy}$ $(x=0,1$, and 3$)$ were produced by melt-spinning and subsequent annealing. The magnetoresistance is negative as in granular $\mathrm{Co}-\mathrm{Cu}$, but its values depend on the kind of rare earth element added and on changes in the microstructure induced by thermal annealing. An addition of 1 at.\% rare earth metal to $\mathrm{Co}_{20} \mathrm{Cu}_{80}$ yields a considerable increase in the magnetoresistance ratio, whereas an addition of 3 at.\% causes a decrease. E.g., by addition of 1 at.\% Dy to $\mathrm{Co}_{20} \mathrm{Cu}_{80}$ and optimal thermal treatment, the value of magnetoresistance ratio measured at $10 \mathrm{~K}$ in a field of $5 \mathrm{~T}$ increases from $-14 \%$ to $-28 \%$. The effect can be attributed to the presence of clusters of hexagonal $\mathrm{Dy}(\mathrm{Co}, \mathrm{Cu})_{5}$, which was ascertained from X-ray diffraction data, or other, metastable rare-earth compounds and paramagnetic rare-earth atoms in the $\mathrm{Cu}$ matrix.

PACS numbers: $75.70 . \mathrm{Pa}, 75.50 . \mathrm{Tt}$

Granular solids consisting of nano-sized particles of ferromagnetic metals dispersed in a nonmagnetic metallic matrix have recently been the subject of particular interest mainly because of their unusual magnetotransport properties. Frequently, the magnetoresistance of such materials is isotropic and negative. This effect is the so-called giant magnetoresistance (GMR). Such granular metals can be derived from supersaturated alloys of immiscible systems, which may be produced by magnetron sputtering [1], mechanical alloying [2] or melt-spinning [3], usually followed by a thermal treatment to prompt a decomposition reaction. A well-known example of a granular system showing the GMR-effect is the $\mathrm{Cu}-\mathrm{Co}$ system. Due to incomplete mixing and/or by a decomposition reaction, ultrafine Co-precipitates in a Cu-rich matrix can be produced [1,3]. The Co-precipitates

*B. Idzikowski acknowledges support by Saxonian Ministry for Sciences and Arts.

tOn leave from International Laboratory of High Magnetic Fields and Low Temperatures, Wroctaw and Institute of Solid State Physics, Bulgarian Academy of Sciences, Sofia, Bulgaria. 
are ferromagnetic single domain particles. The occurrence of GMR is governed by spin-dependent scattering of conduction electrons at or in these particles embedded in a non-ferromagnetic matrix with a high conductivity. GMR is not exclusive to the $3 d$ metal systems, it has also been observed in certain alloys containing rare-earth (RE) elements. However, in this case the mechanism of $4 f$-GMR effect is different and has not yet been fully understood [4]. It is also known that paramagnetic RE atoms in a metallic matrix can show magnetoresistance effects [5].

In this study $\mathrm{Co}_{20} \mathrm{Cu}_{80}$ was modified with small additions of rare earth. In such systems the magnetically ordered components may be Co and $\mathrm{RE}-(\mathrm{Co}, \mathrm{Cu})$ compounds in the Cu-matrix. Ingots with nominal composition $\mathrm{RE}_{x} \mathrm{Co}_{20} \mathrm{Cu}_{80-x}$ ( $\mathrm{RE}=\mathrm{Sm}, \mathrm{Gd}$ or Dy) with $x=0,1$ or 3 were prepared of high purity elements in an arc furnace. To ensure homogeneity they were turned over and melted several times. Ribbons were melt-spun in an Ar filled chamber using a single-roller equipment with a copper wheel. Details of the rapid quenching process are described in Ref. [6]. The dimensions of the obtained ribbons are.1.5-2 $\mathrm{mm}$ and $20-30 \mu \mathrm{m}$ in width and thickness, respectively.

The structure of the samples was characterized by X-ray diffraction analysis using Co $K_{\alpha}$ radiation. Magnetization as a function of temperature was investigated using a SQUID magnetometer between $4.2 \mathrm{~K}$ and room temperature. The electrical resistivity was measured in magnetic fields up to $16 \mathrm{~T}$ in the ribbon plane using the four-probe technique in a temperature range from 5 to $300 \mathrm{~K}$.

Figure 1 shows X-ray diffractograms of melt-spun alloys in as-quenched state or after annealing at $480^{\circ} \mathrm{C}$ for 1 hour. All the alloys contain fcc Co clusters. The positions of peaks due to these clusters are indicated in Fig. 1a. For alloys with RE added, peaks due to rare-earth compounds appear in the diffractograms. Peaks due to possible compounds are indicated by filled symbols in Fig. 1b-d.
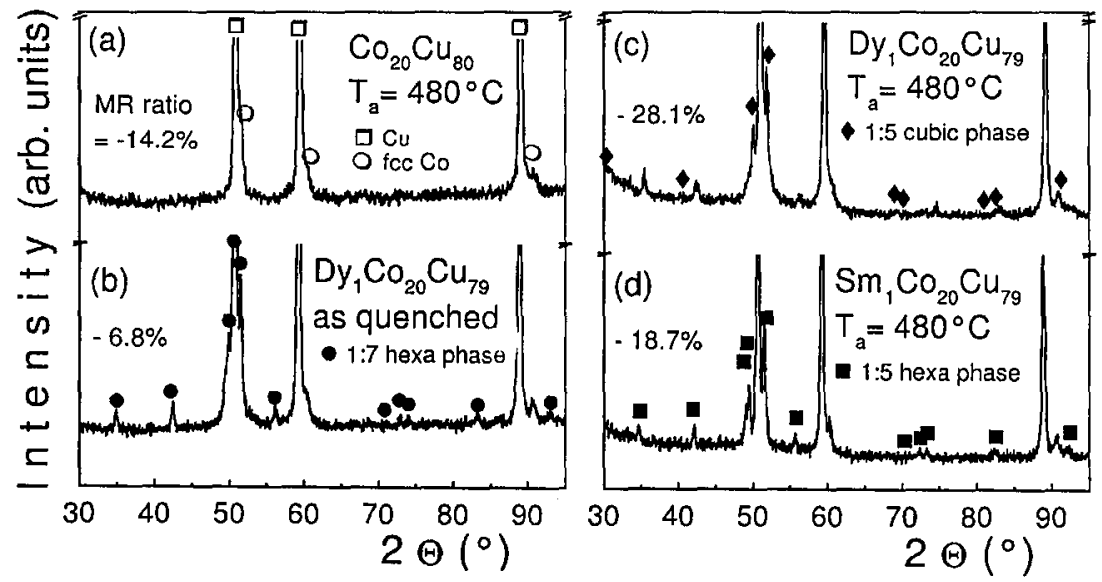

Fig. 1. X-ray diffraction patterns of melt-spun ribbons: (a) annealed $\mathrm{Co}_{20} \mathrm{Cu}_{80}$, (b) $\mathrm{Dy}_{1} \mathrm{Co}_{20} \mathrm{Cu}_{79}$ in as-quenched state, (c) annealed $\mathrm{Dy}_{1} \mathrm{Co}_{20} \mathrm{Cu}_{79}$, and (d) annealed $\mathrm{Sm}_{1} \mathrm{Co}_{20} \mathrm{Cu}_{79}\left(T_{\mathrm{a}}=480^{\circ} \mathrm{C}\right.$ for $\left.1 \mathrm{~h}\right)$. Filled symbols mark positions of peaks due to possible rare earth containing compounds, which may occur in the ribbons (b-d). 
However, assignment of the different compounds to the alloys in Fig. 1b-d does not mean that the respective compound prevails in the samples. The samples seem to contain a mixture of the hexagonal $\mathrm{RECu}_{7}$ phase with $\mathrm{TbCu}_{7}$-type structure and hexagonal $\mathrm{RE}(\mathrm{Cu}, \mathrm{Co})_{5}$ with $\mathrm{CaCu}_{5}$-type structure, which cannot be distinguished from the X-ray diffraction data. Indications of the cubic $\mathrm{RECu}_{5}$ with $\mathrm{AuBe}_{5}$-type structure are also found. This mixture of compounds depends on the kind of RE and the annealing state. The $\mathrm{DyCu}_{7}$ phase exists only in a high temperature range between $775^{\circ} \mathrm{C}$ and $860^{\circ} \mathrm{C}$ [7]. As shown in Ref. [8] this phase can be prepared by rapid quenching to low temperatures, where it is metastable. Upon heat treatment, its decomposition takes place into cubic $\mathrm{DyCu}_{5}$ and pure $\mathrm{Cu}$. At $10 \mathrm{~K}$ both the 1:7 phase and the two 1:5 phases are ferromagnetic. The presence of the cubic 1:5 phase results in an increased magnetoresistance [8]. Thus, the cubic 1:5 phase in our ribbons with Dy is an indication that the metastable 1:7 phase occurs in the as-quenched state. As can be seen from the data in Table, the magnetoresistance ratio $M R=[R(H)-R(0)] / R(0)$ of $\mathrm{Co}_{20} \mathrm{Cu}_{80}$ is increased by the addition of 1 at.\% $\mathrm{RE}$ after optimal annealing. The strongest increase is found for $\mathrm{Dy}_{1} \mathrm{Co}_{20} \mathrm{Cu}_{79}$ with $M R=-28.1 \%$ measured at $T=10 \mathrm{~K}$ in a field of $5 \mathrm{~T}$. The addition of 1 at.\% RE also leads to a stronger increase in $M R$ at lower annealing temperature compared to the annealing effect on $\mathrm{Co}_{20} \mathrm{Cu}_{80}$. But, adding 3 at.\% of $\mathrm{RE}$ markedly reduces $M R$. As shown in Fig. 2, the magnetoresistance of a $\mathrm{Dy}_{1} \mathrm{Co}_{20} \mathrm{Cu}_{79}$ ribbon is hard to saturate at $10 \mathrm{~K}$ in fields up to about $6 \mathrm{~T}$. It can be saturated for $\mathrm{Co}_{20} \mathrm{Cu}_{80}$, $\mathrm{Sm}_{1} \mathrm{Co}_{20} \mathrm{Cu}_{79}$, and $\mathrm{Gd}_{1} \mathrm{Co}_{20} \mathrm{Cu}_{79}$ samples already in a magnetic field of 1-2 $\mathrm{T}$. In small fields, the highest sensitivity of the $M R$-ratios is found for $\mathrm{Gd}_{1} \mathrm{Co}_{20} \mathrm{Cu}_{79}$. Figure 3 shows thermomagnetic curves of the optimally annealed $\mathrm{Dy}_{1} \mathrm{Co}_{20} \mathrm{Cu}_{79}$ sample measured at $5 \mathrm{mT}$. The temperature dependence of magnetization for zero-field (ZFC) and field cooled (FC) samples exhibits spin-glass-like behavior, with freezing (or blocking) temperature below $40 \mathrm{~K}$. The bifurcation of ZFC and FC magnetization starts at room temperature. This indicates a broad distribution

TABLE

Magnetoresistance ratio (in \%) measured at a temperature of $10 \mathrm{~K}$ and magnetic field of $5 \mathrm{~T}$ for melt-spun $\mathrm{Co}_{20} \mathrm{Cu}_{80}$ ribbons modified by $\mathrm{Dy}, \mathrm{Gd}$ or $\mathrm{Sm}$ in as-quenched state (a.q.) and after annealing at different temperatures $T_{\mathrm{a}}$ for $1 \mathrm{~h}$.

\begin{tabular}{l|c|r|r|r|r|r|c}
\hline \hline \multicolumn{1}{c|}{ Samples $/ T_{\mathrm{a}}$} & a.q. & $400^{\circ} \mathrm{C}$ & $420^{\circ} \mathrm{C}$ & $450^{\circ} \mathrm{C}$ & $480^{\circ} \mathrm{C}$ & $500^{\circ} \mathrm{C}$ & $520^{\circ} \mathrm{C}$ \\
\hline $\mathrm{Co}_{20} \mathrm{Cu}_{80}$ & -2.0 & -3.1 & -4.5 & -4.7 & -14.2 & -7.1 & -6.5 \\
$\mathrm{Dy}_{1} \mathrm{Co}_{20} \mathrm{Cu}_{79}$ & -6.8 & -17.8 & -25.8 & -27.7 & -28.1 & -15.0 & -9.1 \\
$\mathrm{Dy}_{3} \mathrm{Co}_{20} \mathrm{Cu}_{77}$ & -4.2 & - & -4.0 & - & -3.9 & - & -1.8 \\
$\mathrm{Gd}_{1} \mathrm{Co}_{20} \mathrm{Cu}_{79}$ & -3.3 & - & -11.8 & - & -17.5 & - & -4.9 \\
$\mathrm{Gd}_{3} \mathrm{Co}_{20} \mathrm{Cu}_{77}$ & -1.1 & - & -2.2 & - & -2.8 & - & -1.0 \\
$\mathrm{Sm}_{1} \mathrm{Co}_{20} \mathrm{Cu}_{79}$ & -5.3 & - & -9.1 & - & -18.7 & - & -5.5 \\
$\mathrm{Sm}_{3} \mathrm{Co}_{20} \mathrm{Cu}_{77}$ & -0.8 & - & -3.1 & - & -5.0 & - & -4.2
\end{tabular}



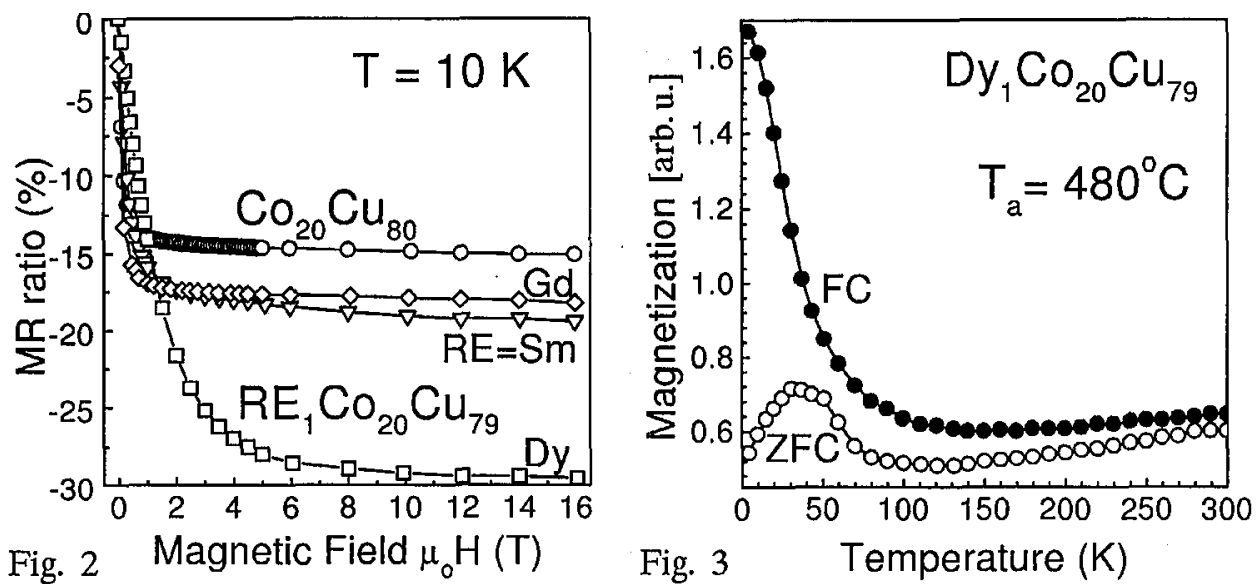

Fig. 2. Magnetoresistance ratio vs. magnetic field of $\mathrm{Co}_{20} \mathrm{Cu}_{80}$ and of $\mathrm{RE}_{1} \mathrm{Co}_{20} \mathrm{Cu}_{79}$ ribbons with $\mathrm{RE}=\mathrm{Dy}, \mathrm{Gd}, \mathrm{Sm}$ annealed at $480^{\circ} \mathrm{C}$ for $1 \mathrm{~h}$. Measuring temperature $T=10 \mathrm{~K}$. Fig. 3. Magnetization as a function of temperature for $\mathrm{Dy}_{1} \mathrm{Co}_{20} \mathrm{Cu}_{79}$ after field cooling (FC) and zero field cooling (ZFC) at $\mu_{0} H=5 \mathrm{mT}$.

of cluster sizes. The decreasing magnetization between $300 \mathrm{~K}$ and about $125 \mathrm{~K}$, could be accounted for by the presence of a small amount of ferromagnetic material.

In conclusion, additions of rare-earth elements to $\mathrm{Co}_{20} \mathrm{Cu}_{80}$ have a remarkable influence on its magnetoresistance. A small amount of RE (1 at.\%) increases $M R$ but higher amounts lead to a reduction of $M R$. The effect seems to depend also on the kind of rare earth element added, with the strongest increase observed for $\mathrm{Dy}_{1} \mathrm{Co}_{20} \mathrm{Cu}_{79}$. The effect may be due to the presence of rare earth compounds like $\mathrm{DyCu}_{7}$ and/or $\mathrm{Dy}(\mathrm{Co}, \mathrm{Cu})_{5}$.

\section{References}

[1] A. Berkowitz, J.R. Mitchell, M.J. Carey, A.P. Young S. Zhang, F.E. Spada, F.T. Parker, A. Hütten, G. Thomas, Phys. Rev. Lett. 68, 3745 (1992).

[2] S.M. Thompson, J.F. Gregg, C.R. Staddon, D. Daniel, S.J. Dawson, K. Ounadjela, J. Hammann, C. Fermon, G. Saux, K. O'Grady, S.J. Grieves, J.M.D. Coey, A. Fagan, Philos. Mag. B 68, 923 (1993).

[3] J. Wecker, R. von Helmoldt, L. Schultz, K. Samwer, Appl. Phys. Lett. 62, 1985 (1993).

[4] V. Sechovský, L. Havela, K. Prokes, H. Nakotte, F.R. de Boer, E. Brück, J. Appl. Phys. 76, 6913 (1994).

[5] J.C. Ousset, G. Carrere, J.P. Ulmet, S. Askenazy, G. Creuzet, A. Fert, J. Magn. Magn. Mat. 24, 7 (1981).

[6] B. Idzikowski, K. Nenkov, A. Handstein, A. Hütten, K.-H. Müller, Acta Phys. Pol. A 92, 307 (1997).

[7] K.H.J. Buschow, A.M. van Diepen, H.W. de Wijn, J. Appl. Phys. 41, 4609 (1970).

[8] K.-H. Müller, B. Idzikowski, D. Eckert, K. Nenkov, H.-J. Engelmann, M. Wolf, IEEE Trans. Magn. 33, 3565 (1997). 